\title{
Challenges in the promotion of lightning protection know-how in developing world
}

\begin{abstract}
The natural and induced conceptual barriers in promoting scientifically proven lightning protection technologies in several developing countries are analyzed in depth, based on several long term investigations conducted in South, South East and Middle East Asian regions. Most of these countries emerge as huge markets for lightning protection systems, hence the outcomes of this study are highly beneficial for the business community that markets lightning protection technology, commercial sector that seeks lightning protection and the engineering consultants that look forward to render their services in developing countries. As it is figured out, the major drawbacks in designing or purchasing good lightning protection systems are; the lack of flow of scientific information to the local engineer-level, the technical lapses in analyzing transient conditions, the low quality of electrical networking/wiring practices, the majority of decision-makers being non-engineers, the ignorance of engineers/consultants in conducting proper risk assessment, the lack of up-todate codes and guidelines at national level, the flooding of the market with fake products and the unethical perks offered by the vendors to the consultants and decision makers. These shortfalls lead to dangerous grounding practices, inappropriate selection of lightning protection devices, excessively high cost of protection, and unacceptable level of system failure and low level of reliability. These undesirable conditions have highly negative impact on the impression and perception of general public on lightning protection devices and methodologies, thus centuries of scientific investigations on the subject becomes futile at application-level.
\end{abstract}

